\title{
Inequality, chronic undernutrition, maternity, and diabetes mellitus as the determinant of anemia among ever- married women in Bangladesh
}

\author{
G. M. Rabiul Islame(1)
}

\begin{abstract}
Background: Anemia is a public health concern at a global level. This study aims to delineate the association between household economic inequalities, and anemia among reproductive age group women in Bangladesh, along with other confounders.

Methods: A cross-sectional population sample from Bangladesh Demographic and health survey data comprising of 5920 reproductive age group women aged between 15 and 49 years was used in this study. The analyses were performed through the application of proportional odds into four models (viz., Model:1 socio-economic, Model:2 socio-demographic factors, Model 3: diabetics and maternity statis, Model 4: nutritional status.)

Results: The respondents from low and medium socioeconomic status (SES) households vs. richest households were $1.90(95 \% \mathrm{Cl}, 1.65,2.17 ; p<.01)$ and $1.41(95 \% \mathrm{Cl}, 1.12,1.78 ; p<.01)$ times more likely to suffer from anemia (Model 1). From the model 2 it appears that he likelihood of being anemic reduces for the low and medium SES groups vs. high SES group when sociodemographic variables are added $(\mathrm{OR}, 1.69,95 \% \mathrm{Cl}, 1.43,1.99$ and OR, 1.35, $95 \% \mathrm{Cl}, .07,1.70 ; p<0.01$, respectively). Model 3 evident that after adding the variables of diabetes and maternity status, the association between having anemia belonging to low and medium SES vs. high SES becomes weaker (OR1.36, 95\% Cl,0.85,2.15 and OR, 1.15, 95\% Cl, 0.6,2.19; $p>.05$, respectively). Moreover, the strength of the association between anemia and the subjects with pregnant vs. the subjects without these (OR: $1.7(1.12,4.02 ; p<$ 0.05) 1.47(0.11,3.399; $\mathrm{p}<0.05)$ conditions was reduced after factoring body mass index (BMl, model 4). Besides, thin women $\left(\mathrm{MBl}<18.50 \mathrm{Kg} / \mathrm{m}^{2}\right)$ shows significantly become more likely to be anemic in comparison to women of normal BMI (OR:1.34, .92,1.96; $p<0.05)$ (model 4).
\end{abstract}

Conclusions: BMI, pregnancy, and diabetes mellitus were observed to be significantly associated with anemia, and the strength of the association was low with anemia and socioeconomic inequality.

Keywords: Anemia, Reproductive age group, Inequality, Diabetes, Maternity, BMI

Correspondence: rabi-ttc@sust.edu; rabiat14@yahoo.com

Department of Food Engineering and Tea Technology, Shahjalal University of

Science and Technology, Sylhet 3114, Bangladesh

(c) The Author(s). 2021 Open Access This article is licensed under a Creative Commons Attribution 4.0 International License, which permits use, sharing, adaptation, distribution and reproduction in any medium or format, as long as you give appropriate credit to the original author(s) and the source, provide a link to the Creative Commons licence, and indicate if changes were made. The images or other third party material in this article are included in the article's Creative Commons licence, unless indicated otherwise in a credit line to the material. If material is not included in the article's Creative Commons licence and your intended use is not permitted by statutory regulation or exceeds the permitted use, you will need to obtain permission directly from the copyright holder. To view a copy of this licence, visit http://creativecommons.org/licenses/by/4.0/ The Creative Commons Public Domain Dedication waiver (http://creativecommons.org/publicdomain/zero/1.0/) applies to the data made available in this article, unless otherwise stated in a credit line to the data. 


\section{Background}

Despite significant advances in the field of medicine and healthcare, anemia continues to be a major public health problem worldwide [1]. Individuals from low- and middle-income countries are particularly affected [2]. In 2011, the World Health Organization (WHO) estimated that globally half a billion women are affected with anemia, among them 29\% are nonpregnant, and $38 \%$ are pregnant women, and the prevalence of anemia was the highest in south Asia and central and west Africa [3]. Between 1990 and 2010, increasing efforts were made to combat anemia but the global burden of the disease still remains surprisingly substantial [1]. Women of reproductive age are especially vulnerable to the disease, and a 50\% reduction is the second global nutrition target for 2025, set forth by the World Health Assembly [4].

Anemia during pregnancy is a risk factor for preterm delivery and subsequent low birth weight, and possibly for inferior neonatal health $[5,6]$. The high prevalence of anemia is of great concern because it is associated with cognitive, motor, and socio-emotional abilities [7]. These abilities are linked with academic achievement and economic productivity [8]. Anemia is a result of a wide variety of causes that are typically known to coexist. There is a close association with diabetes mellitus and anemia as well as pregnancy [9]. Besides, in Bangladesh, the prevalence of diabetic patient is increasing [10]. Other factors contributing to anemia include iron deficiency; other micronutrient deficiencies such as folate, vitamin $\mathrm{B} 12$, and vitamin-A; diabetes; chronic kidney disease (CKD); parity; acute and chronic infections; and chronic undernutrition $[11,12]$. Socioeconomic factors have also been associated with anemia as food insecurity, inadequate water, sanitation and hygiene have been shown to increase the risk of infectious diseases and decreasing the availability and consumption of micronutrient-rich foods [13, 14]. In Bangladesh, analysis of the national representative data recently released by the Demographic and Health Surveys (BHDS) 2011, accurately summarizes the magnitude of the problem among women of reproductive age. In the BDHS 2011 sample, the prevalence of anemia among reproductive age group women between the ages of 15 and 49 years was approximately $42 \%$. Thirty-six percent of these women were classified as mildly anemic (hemoglobin < 110-119.99 g/L), 7\% as moderately anemic (hemoglobin $<80-109.99 \mathrm{~g} / \mathrm{L})$, and $1 \%$ as severely anemic (hemoglobin < $80 \mathrm{~g} / \mathrm{L}$ ) [15]. Clearly, anemia in women of reproductive age is of public health concern and is a significant contributor to comorbidities in Bangladesh. Given the multifactorial nature of this disease, anemia prevention and treatment require an integrated approach. Therefore, it is imperative to identify the factors associated with anemia in order to effectively combat the disease.

The association between socioeconomic status and anemia has been studies in Southeast Ethiopia, Northeast Ethiopia, Andhra Pradesh India, Mexico Peru, and Egypt demonstrated that women in poorer households tend to be more anemic and undernourished as compared to those in better households [16-19]. However, despite the heavy burden of anemia related comorbidity in Bangladesh, no epidemiologic studies have been conducted in order to elucidate the risk factors associated with anemia emphasizing inequality among women of reproductive age in Bangladesh. Though, Kamruzzaman et al., 2016 analyzed anemia and its contributing factor in Bangladesh but did not emphasize wealth- or incomerelated inequality. Therefore, the aim of this study was to find what variables would show a strong association with varying severity of anemia in order "to contribute to policymaking and be instrumental in the programs designed to prevent anemia in Bangladeshi women.

\section{Methods \\ Study settings}

We used data from Bangladesh Demographic and Health Surveys (DHS) collected by ICF International, which were conducted from July 8 to December 27, 2011 in collaboration with the National Institute of Population Research and Training (NIPORT) of the Ministry of Health and Family Welfare of Bangladesh, and Mitra and Associates, a Bangladeshi research firm [15].

Bangladesh has seven administrative divisions: Barisal, Chittagong, Dhaka, Khulna, Rajshahi, Rangpur, and Sylhet. Each division is subdivided into district, and each district into sub-district. Thus, the divisions allow the country as a whole to be easily separated into rural and urban areas. The sampling in BDHS was done through a stratified, multistage cluster selection approach. In the first stage, 600 enumeration areas (EAs), of which 207 were from urban areas and 393 were from rural areas, were selected. This primary sampling EAs were selected from the sampling frame created for the 2001 Bangladeshi census. In the second stage, a systematic sample of 30 households on average was selected per EA to provide statistically reliable estimates of key demographic and health variables for the country, for urban and rural areas separately and for each of the seven divisions of the country. Next, a total of 1800 selected households, interviews were successfully completed in 17,141 households. Finally, within these households, a total of 18,222 reproductive age group were successfully interviewed. A total of 5920 reproductive age group women aged between 15 and 49 years who resided in one-third of the randomly selected households were selected as the subjects for the biomarker assay for anemia study. After 
excluding the subjects for whom associated hemoglobin data were missing, a total of 5886 women were selected for the final analysis.

\section{Outcome}

In this study, hemoglobin concentration was used to diagnose anemia. The Hemocue system was used to estimate the concentration of hemoglobin in the capillary blood. The prevalence was adjusted for individual sample weight [20], altitude and smoking status using the formula suggested by the Center for Disease Prevention of United State [15] adopted by WHO [21] and BDHS [22], as hemoglobin concentrations differ substantially depending on the altitude and smoking status. For the purpose of this study, "anemia" was defined as per the 2011 WHO's guidelines for the diagnosis of anemia; the same definition was also adopted by the Demographic Health Surveys [21, 22]. Briefly, in the case of pregnant women, a hemoglobin concentration of less than $70 \mathrm{~g} / \mathrm{L}$ was used to define severe anemia, between 70 and 99.99 $\mathrm{g} / \mathrm{L}$ was used for defining moderate anemia while 100$109.99 \mathrm{~g} / \mathrm{L}$ was taken to correspond to mild anemia. In non-pregnant women, a hemoglobin concentration of less than $80 \mathrm{~g} / \mathrm{L}$ was used to define severe anemia, 80 $109.99 \mathrm{~g} / \mathrm{L}$ for moderate anemia, and $110-119.99 \mathrm{~g} / \mathrm{L}$ to correspond to mild anemia. However, as only $0.14 \%$ of women were classified as being severely anemic, for the purposes of the regression modeling, the severe and moderate groups were combined to create a severe/ moderate category (hemoglobin concentration of $<100$ $\mathrm{g} / \mathrm{L}$ in pregnant women and less than $110 \mathrm{~g} / \mathrm{L}$ in nonpregnant women) to avoid the problems of zero cell counts in the models.

\section{Explanatory variables}

Socioeconomic status, defined as the wealth status of the individual, was used as a key predictor in this study. The wealth index, used in the BDHS survey, has been used in many previous DHS and other country-level surveys to measure the inequalities in a variety of confounders such as household characteristics, health, and other services, and in health outcomes [15]. This serves as an indicator of household wealth level that is found to be consistent with both expenditures as well as income measures [23]. The BDHS calculated the index using household asset data that comprises information on the availability of electricity, housing facilities, possession of household durable good and ownership of a homestead and land via principal components analysis. In this study, the wealth index score of the 2011 BDHS survey was used as a proxy for SES and inequality was measured by dividing the wealth index into tertiles and categorizing them as "low" "medium" and "high". This study also included other related explanatory variables, such as respondent education level (none/primary school/secondary school or higher), place of residence (rural/ urban), employment status (employed/unemployed) sex of households head, number of child, menopausal age, family size, maternity and nutritional status (BMI), etc. (see details in Table 1).

\section{Ethical considerations}

The data collection procedure for the BDHS was carried out with the approval of the ORC Macro-institutional review board (ICF Macro Project Number: 631561.0.000.00.091.01), and National Research Ethics Committee, Bangladesh Medical Research Council (BMRC/NREC/2010-2013/537). As per the guidelines of the BDHS, prior to the interview, informed consent was obtained from individual respondents and this was followed by an oral explanation given by the interviewers. The respondents were informed of the voluntary nature of the survey, the potential risks involved in participation, the purpose of gathering the data (assessment of health needs and planning health services) and the confidentiality of the results of the individual interview along with the free of charge nature of the examination.

\section{Statistical analysis}

Pearson's chi-square test was used to determine statistically significant differences between the categories of the $\mathrm{CDC} / \mathrm{WHO}$ hemoglobin grouping variable in relation to other explanatory variables. We also used the concentration indices to quantify the degree of socioeconomic related inequality of being anemic. Concentration indices are frequently used to measure inequality in one variable over the distribution of another. Most commonly, they are applied to the measurement of socioeconomicrelated inequality in health [28]. Therefore, we also calculated the concentration index of being underweight, diabetes, and pre-diabetes across the SES as variables also consider as an independent confounder.

Ordered logit using maximum likelihood estimation was used to identify the socioeconomic and other determinants of anemia status. To account for the complex survey design, this study included strata (i.e.,7 division of Bangladesh) and clustering variable (primary sampling unit) by using the survey option in Stata. Four models were tested in the ordered logit models to identify the consequence of the different variables associated with anemia (Table 1). Model 1 included SES, a variable that indicated the level of household wealth. This allowed this study to assess whether different SES groups exhibit differences in the likelihood of being anemic. In Model 2, sociodemographic variables were introduced in addition to socioeconomic status. Two additional models were also tested considering the variables already 
Table 1 The variables tested for the association with anemia in the logistic regression Models 1-4

\begin{tabular}{|c|c|c|}
\hline Model 1: & Socio-economic status & Household-level wealth index (Low, Medium or High) \\
\hline \multirow[t]{8}{*}{ Model 2: } & \multicolumn{2}{|l|}{ Model 1 variable and Sociodemographic variables } \\
\hline & Respondent Highest Education Level: & None/completed primary/completed secondary or higher \\
\hline & Place of residence: & Rural/Urban \\
\hline & Employment status: & Employed/Not employed \\
\hline & Sex of house old head: & Male/Female \\
\hline & Number of children: & None/One/Two/Three or more \\
\hline & awomen reproductive age: & $\begin{array}{l}\text { Early reproductive ( }<20 \text { years)/Middle reproductive ( } 20-38 \text { years) } \\
\text { Late reproductive ( } 39-42 \text { years)/Early premenopause ( } 43-46 \text { years) } \\
\text { /Late premenopause }(<46 \text { years) }\end{array}$ \\
\hline & Family size: & $\begin{array}{l}\text { Small/Large (Number of family members } 7 \text { or over which is based } \\
\text { on mean number of members in a household). }\end{array}$ \\
\hline \multirow[t]{3}{*}{ Model 3: } & \multicolumn{2}{|l|}{ Model 2 variables and diabetes and maternity status } \\
\hline & Maternity status: & Pregnant/Lactating/Neither \\
\hline & ${ }^{\mathrm{b}}$ Fasting plasma glucose levels: & Normal/Peri diabetic/Diabetes \\
\hline \multirow[t]{2}{*}{ Model 4: } & Model 3 variables and BMI & \\
\hline & & $\begin{array}{l}\text { Underweight/thin }\left(<18.50 \mathrm{~kg} / \mathrm{m}^{2}\right) \text {; Normal }\left(18.50,24.99 \mathrm{~kg} / \mathrm{m}^{2}\right) \text {; } \\
\text { Overweight }\left(25,30 \mathrm{~kg} / \mathrm{m}^{2}\right) \text {; Obese }\left(>30 \mathrm{~kg} / \mathrm{m}^{2}\right)\end{array}$ \\
\hline \multicolumn{3}{|c|}{$\begin{array}{l}\text { a The menopausal age is considered from the study of Bharadwaj et al. [24] } \\
\text { b The } 2011 \text { BDHS measured the blood glucose level using the HemoCue 201+ blood glucose analyzer (Teleflex Medical L.P., Markham, Canada) in whole blood } \\
\text { obtained by finger prick from the capillaries in the middle or ring finger after an overnight fasting-an approach that is widely used in resource-limited settings. } \\
\text { The definition of "diabetes" is adopted from the Demographic Health Surveys report, that is, fasting plasma glucose greater than or equal to } 7.0 \mathrm{mmol} / \mathrm{L} \text { or use of } \\
\text { anti-diabetic medication. Subjects with "pre-diabetes" were defined as subjects with fasting plasma glucose concentrations in the range of } 6.1-6.9 \mathrm{mmol} / \mathrm{L} \text { and } \\
\text { not taking anti-diabetic medication [25]. For this classification of "diabetes" and "prediabetes", the cutoff point for fasting plasma glucose was according to the } \\
\text { recommendation of the American Diabetes Association [26] and International Diabetes Federation [27] }\end{array}$} \\
\hline
\end{tabular}

included in the earlier models. Model 3 introduced diabetes and maternity as factors while Model 4 used BMI. The variables are detailed in Table 1 . The models allowed for an in-depth analysis of the significance of SES as correlated with anemia status while controlling for a range of other factors. In addition, this methodology allowed for the identification of factors that reduced the significance of SES in each model thus enabling the identification of variables associated with SES as well as hemoglobin concentrations in women. Analyses were performed with Stata (version 13; Stata Corp LP).

\section{Results}

\section{Descriptive analysis}

Table 2 summarizes the proportion of women in each anemia group, when the groups were classified using the explanatory variables and the chi-square test. The chisquare test indicated that the differences observed in the percentage of women classified as anemic based on factors such as SES, respondent education level, place of residence, age, maternity status, fasting blood plasma glucose level and nutritional status, were statically significant $(p<0.05)$. The concentration index indicates that the trends of anemia, underweight, prediabetes and diabetes were stronger in the individuals belonging to low SES category (Table 3).

\section{Effect of household economic inequality and other confounders}

The results of the ordered logit models are presented in Table 4. The women from low and medium SES groups showed the higher odds (OR, 1.90, 95\% CI, 1.65-2.17; $p<.01$ and OR, 1.41, 95\% CI, 1.12-1.78; $p<.01)$ of being anemic when compared to the high SES group in an unadjusted model (Model 1). From Model 2, it is evident that women with no education or primary educational attainment were more likely to be anemic in comparison to those who had completed secondary or higher education (OR, 1.22, 95\% CI, 1.05-1.42 \& OR, 1.15 95\% CI, $1.01-1.3 ; p<0.01$, respectively).

The likelihood of being anemic appear as slightly lowered for low and medium SES groups (model 2) in comparison to the high SES group when sociodemographic variables were added to the bivariate analysis (Model 1) (OR, 1.9, 95\% CI, 1.65-2.17 to OR, 1.69, 95\% CI, 1.431.99 and OR, $1.41,95 \% \mathrm{CI}, 1.21-1.78$ to OR,1.35, 95\% CI,1.07-1.7; $p<0.01$, respectively).

After adding the variables for maternity and diabetes the likelihood of having anemia in the subjects from low and medium SES households vs. high SES households and individuals having primary and secondary or higher secondary education vs. their counterpart with no educational attainment became insignificant $(p>0.05)$. The maternity status was also found to be a significant factor contributing to 
Table 2 Percentages of women with anemia by standard of explanatory variables $(N=5886)$

\begin{tabular}{|c|c|c|c|c|c|c|}
\hline \multirow[b]{2}{*}{ Variable } & \multirow[b]{2}{*}{ n (\%) } & \multicolumn{3}{|c|}{ Anemia status by hemoglobin level\% } & \multirow[b]{2}{*}{ Chi-square result } & \multirow[b]{2}{*}{$P$ value } \\
\hline & & Not anemic & Mild & $\begin{array}{l}\text { Moderate/ } \\
\text { Sever }\end{array}$ & & \\
\hline \multicolumn{7}{|l|}{ Socio-economic status } \\
\hline Low & $4265(72.46)$ & 54.59 & 37.50 & 7.90 & 92.63 & $<.01$ \\
\hline Medium & $434(7.37)$ & 59.38 & 37.05 & 3.57 & & \\
\hline High & $1187(20.17)$ & 70.94 & 24.00 & 5.06 & & \\
\hline \multicolumn{7}{|l|}{ Socio-demographic factors } \\
\hline \multicolumn{7}{|l|}{ Highest Education level } \\
\hline No education & $2605(44.26)$ & 54.46 & 37.00 & 8.54 & 46.88 & $<.01$ \\
\hline Completed primary & $2553(43.37)$ & 59.78 & 34.23 & 5.98 & & \\
\hline Completed secondary or higher & $728(12.37)$ & 67.57 & 27.67 & 4.76 & & \\
\hline \multicolumn{7}{|l|}{ Place of residence } \\
\hline Rural & $3863(65,63)$ & 55.92 & 36.81 & 7.27 & 26.11 & $<.01$ \\
\hline Urban & $2023(34.37)$ & 62.91 & 30.50 & 6.52 & & \\
\hline \multicolumn{7}{|l|}{ Employment status } \\
\hline Employed & $853(85.49)$ & 58.35 & 34.62 & 7.04 & 0.50 & .80 \\
\hline Not employed & $5027(14.51)$ & 57.33 & 35.68 & 6.99 & & \\
\hline \multicolumn{7}{|l|}{ Sex of house old head } \\
\hline Male & $5301(90.06)$ & 57.95 & 34.86 & 7.18 & 1.93 & .38 \\
\hline Female & $585(9.94)$ & 61.12 & 33.52 & 5.36 & & \\
\hline \multicolumn{7}{|l|}{ Number of child } \\
\hline No child & $2903(39.10$ & 58.09 & 35.01 & 6.90 & 2.49 & .87 \\
\hline One & $2145(36.44)$ & 57.61 & 35.01 & 7.39 & & \\
\hline Two & $670(11.38)$ & 60.87 & 32.34 & 6.80 & & \\
\hline Three or more & $168(2.85)$ & 58.20 & 36.38 & 5.42 & & \\
\hline \multicolumn{7}{|l|}{ Age } \\
\hline Early reproductive & $889(15.10)$ & 57.13 & 35.18 & 7.69 & 16.13 & .04 \\
\hline Middle reproductive & $3502(59.50)$ & 58.68 & 34.65 & 6.67 & & \\
\hline Late reproductive & $637(10.82)$ & 62.70 & 31.21 & 6.09 & & \\
\hline Early premenopause & $488(8.29)$ & 52.78 & 34.21 & 9.01 & & \\
\hline Late premenopause & $370(6.29)$ & 56.01 & 36.20 & 7.79 & & \\
\hline \multicolumn{7}{|l|}{ Family size } \\
\hline Small & $4835(82.14)$ & 57.93 & 34.77 & 7.30 & 3.24 & .19 \\
\hline Large & $1051(17.86)$ & 69.60 & 34.62 & 5.78 & & \\
\hline \multicolumn{7}{|l|}{ Maternity status } \\
\hline Pregnant & $372(6.32)$ & 47.92 & 38.20 & 13.88 & 83.17 & .01 \\
\hline Lactating & $1356(23.06)$ & 58.10 & 34.11 & 7.79 & & \\
\hline Neither & $4158(70.06)$ & 61.61 & 32.29 & 6.10 & & \\
\hline \multicolumn{7}{|l|}{ Diabetes } \\
\hline Normal & $5076(86.25)$ & 59.67 & 33.59 & 6.74 & 1.26 & .04 \\
\hline Prediabetic & $523(8.87)$ & 60.89 & 35.10 & 4.01 & & \\
\hline Diabetic & $287(4.86)$ & 59.95 & 32.70 & 7.36 & & \\
\hline \multicolumn{7}{|l|}{$\mathrm{BMI}^{* *}$} \\
\hline Underweight (<18.50) & $1395(23.86)$ & 49.58 & 42.26 & 8.15 & 94.68 & $<.01$ \\
\hline
\end{tabular}


Table 2 Percentages of women with anemia by standard of explanatory variables $(N=5886)$ (Continued)

\begin{tabular}{|c|c|c|c|c|c|c|}
\hline \multirow[b]{2}{*}{ Variable } & \multirow[b]{2}{*}{ n (\%) } & \multicolumn{3}{|c|}{ Anemia status by hemoglobin level\% } & \multirow[b]{2}{*}{ Chi-square result } & \multirow[b]{2}{*}{$P$ value } \\
\hline & & Not anemic & Mild & $\begin{array}{l}\text { Moderate/ } \\
\text { Sever }\end{array}$ & & \\
\hline Normal $(18.50,24.99)$ & $3422(58.20)$ & 58.44 & 34.22 & 7.35 & & \\
\hline Overweight $(25,30)$ & $886(14.81)$ & 68.91 & 26.22 & 4.87 & & \\
\hline Obese (> 30) & $183(3.13)$ & 72.70 & 34.67 & 2.63 & & \\
\hline
\end{tabular}

"Weight gain was adjusted incase of pregnancy to calculate the BMI [29], that also adopt by BDHS [15]

anemia in Model 4. The pregnant women were observed to be approximately two times more prone to being mild anemic (OR, 1.70, 95\% CI, 1.12-4.02; $p<.05)$ while lactating women appeared to be insignificantly (OR, 1.47, 95\% CI, $0.11-3.99 ; p>0.05)$ anemic as compared to women who were neither pregnant nor lactating. Diabetes mellitus was found as an associate factor of anemia in the full model (Model 4). Women who were suffering from diabetes mellitus were observed to have $74 \%$ higher chance of being 1.74 times, (OR, 1.74, 95\% CI 1.02-3.86; $p<0.05)$ for being mildly, moderately or severely anemic as compared to the subjects with normal blood plasma glucose levels. The overweight women with BMI in the range of $25-30 \mathrm{~kg} / \mathrm{m}^{2}$ were observed to be approximately two times less likely to be anemic than those with a normal BMI (OR, 0.62, 95\% CI, 0.39-0.97; $p<.05)$. Similarly, the women belonging to the early reproductive $(<20$ years) age group were observed to be around $38 \%$ times less likely to be anemic than those who belonged to the late reproductive age group (OR, .62, 95\% CI, .39-.98; $p<.05$ ) (Model 4).

It was evident from Models 3 and 4 that after controlling the variable for nutritional status (BMI), the strength of the associations between anemia and pregnancy status became low (OR, 1.74, 95\% CI, 1.12-4.20; $p<0.01$ to OR, $1.7,95 \% \mathrm{CI}, 1.12-4.20 ; p<0.05$ vs. subject neither pregnant or lactating).

\section{Discussion}

\section{Effect of household socioeconomic status on anemia}

The results of this study indicated that the hypothesis correlating SES and anemia was partially supported
(Model 1 and 2). In developing countries, it is well established that the people belonging to low SES groups suffer from problems such as poor housing, malnutrition, overcrowding, pollution, and increased exposure to infectious diseases [30, 31]. In comparison to high SES women, the women of the lower SES group were at a higher risk for anemia; this can be attributed to the factors such as the lack of access to the subject belonging to low SES own income or resources which in turn results in the lack of decision-making power and autonomy regarding issues such as free movement for treatment, antenatal care, medical facilities, education, etc. In addition, women belonging to the low SES category may also experience higher rates of infection as a result of poor sanitation, gynecological morbidity, and sexually transmitted diseases [32].

\section{Inference of demographics, diabetes, maternity, and BMI}

The results evidence the fact that upon factoring in sociodemographic parameters with Model 1, the likelihood of the members of the low and medium SES group being anemic decreased as compared to the higher SES group. Among the sociodemographic factors analyzed in this study, the respondents with no education or those with only primary education had a higher chance of being anemic as compared to the women with higher educational attainment. These results are in parallel with a similar investigation conducted by Bentley and Griffiths for the National Family Health Survey 1998/99 (NFHS2) wherein the authors discerned a similarity in the prevalence and determinants of anemia in the women in

Table 3 Summary measures of SES inequality and the prevalence of anemia, underweight, diabetes and prediabetes among reproductive age group women aged 15 to 49 years

\begin{tabular}{llll}
\hline Variable & Concentration index & Standard error (SE) & $\boldsymbol{P}_{\text {-value }}$ \\
\hline Underweight women & -.52 & .03 & $<.001$ \\
Anemic women & -.42 & .01 & .002 \\
Pre-diabetic women & -.32 & .01 & .04 \\
Diabetic women & -.30 & .04 & .02 \\
\hline
\end{tabular}

C Obtained by the formula $2 \sigma^{2}{ }_{r}\left(h_{i} / \mu\right)=a+\beta r_{i}+\varepsilon_{i,} h$ is the health variable whose inequality is being measured, $\mu$ is its mean, $r_{i}$ is the ith individual's fractional rank (for example if a women is underweight and which SES group she is belonging) in the socioeconomic distribution, $\sigma^{2}$, is the variance of the fractional rank, The estimate $\beta$ is equal to the concentration index, $r_{i}=$ underweight women, anemic women, pre-diabetic women, diabetic women a is constant (underweight women $=.65$, anemic women $=.95$, pre-diabetic women $=.94$, diabetic women $=.84$ ) and $\varepsilon_{i}$ is the error term. Concentration index has a negative value when the health indicator is concentrated among the disadvantaged; A positive value when the health indicator is concentrated among the advantaged; When there is no inequality the value is equals 0 ; the theoretical maximum is \pm 1 
Table 4 The determinants of anemia in women in Bangladesh (obtained from ordinal logistic regression models) $(\mathrm{N}=5886)$

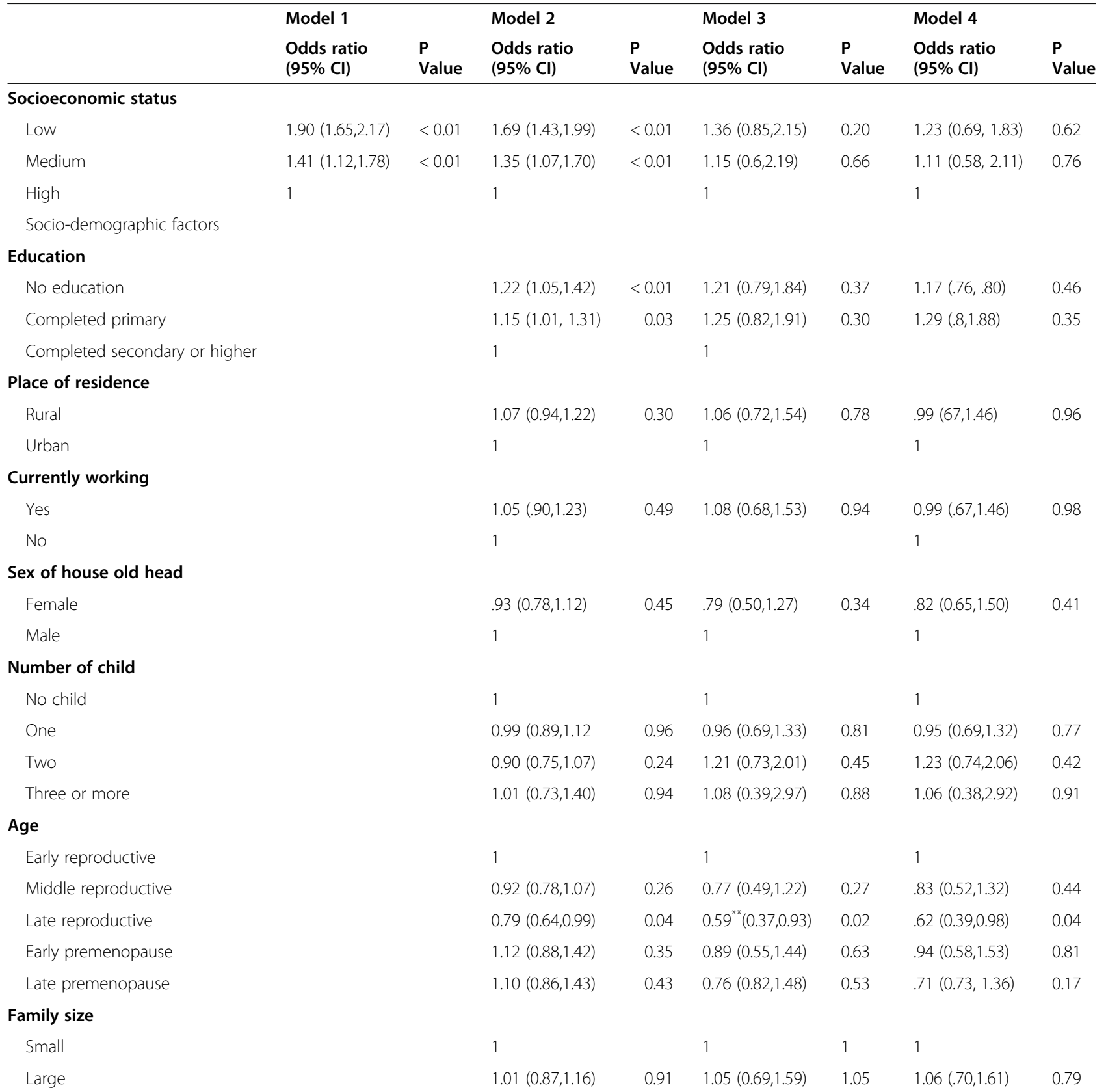

Diabetics and Maternity status

\section{Maternity status}

$$
\begin{aligned}
& \text { Pregnant } \\
& \text { Lactating } \\
& \text { Neither }
\end{aligned}
$$

\section{Fasting plasma glucose levels}

Normal

Prediabetic

Diabetic

$\begin{array}{llll}1.74(1.12,4.20) & <0.01 & 1.7(1.12,4.02) & 0.03 \\ 1.62(1.09,3.70) & 0.03 & 1.47(0.11,3.99) & 0.14 \\ 1 & & 1 & \\ & & & \\ 1 & & 1 & \\ .67(0.39,1.15) & 0.15 & .68(0.39,1.70) & 0.17 \\ 1.67(0.78,3.49) & 0.18 & 1.74(1.02,3.68) & 0.04\end{array}$


Table 4 The determinants of anemia in women in Bangladesh (obtained from ordinal logistic regression models) $(\mathrm{N}=5886)$ (Continued)

\begin{tabular}{|c|c|c|c|c|c|c|c|c|}
\hline & \multicolumn{2}{|l|}{ Model 1} & \multicolumn{2}{|l|}{ Model 2} & \multicolumn{2}{|l|}{ Model 3} & \multicolumn{2}{|l|}{ Model 4} \\
\hline & $\begin{array}{l}\text { Odds ratio } \\
(95 \% \mathrm{Cl})\end{array}$ & $\begin{array}{l}P \\
\text { Value }\end{array}$ & $\begin{array}{l}\text { Odds ratio } \\
(95 \% \mathrm{Cl})\end{array}$ & $\begin{array}{l}\mathrm{P} \\
\text { Value }\end{array}$ & $\begin{array}{l}\text { Odds ratio } \\
(95 \% \mathrm{Cl})\end{array}$ & $\begin{array}{l}P \\
\text { Value }\end{array}$ & $\begin{array}{l}\text { Odds ratio } \\
(95 \% \mathrm{Cl})\end{array}$ & $\begin{array}{l}P \\
\text { Value }\end{array}$ \\
\hline \multicolumn{9}{|l|}{ Nutritional status } \\
\hline \multicolumn{9}{|l|}{ BMI } \\
\hline Underweight $(<18.50)$ & & & & & & & $1.34(.92,1.96)$ & 0.04 \\
\hline Normal $(18.50,24.99)$ & & & & & & & 1 & \\
\hline Overweight $(25,30)$ & & & & & & & $.62(.39,0.97)$ & 0.13 \\
\hline Obese (> 30) & & & & & & & $.66(.30,1.45)$ & 0.30 \\
\hline
\end{tabular}

Andhra Pradesh, India [16]. In their study, Bentley and Griffiths demonstrated that in Andhra Pradesh, adding the variable of maternal education causes a reduction in the odds of being anemic for urban and rural women belonging to the medium and high SES groups as compared to high urban women [16].

The analysis of the results obtained from Model 3 indicates that the addition of diabetics and maternity status reduces the strength of association between having anemia with SES and the education level. This observation can be attributed to the fact that in Bangladesh fasting plasma glucose levels and maternity status are more prominent factors related to anemia as compared to SES and education levels. The precise relationship between diabetics and anemia could not be elucidated in this study. Several previously published studies have indicated that diabetes does not directly cause anemia, but certain complications associated with diabetes can contribute to the phenomenon. For example, both diabetesrelated kidney disease (nephropathy) and nerve damage (neuropathy) can be instrumental to the development of anemia [33, 34]. Moreover, individuals suffering from diabetes can also have anemia as a result of not eating well or of having a condition that interferes with the proper absorption of nutrients.

The results of this study strongly indicate that women who are pregnant are more likely to be anemic as compared to women who are neither lactating nor pregnant (Models 3). Interestingly, as is evident from Models 3 and 4 , the significance of the association between pregnancy reduces after controlling BMI. In developing countries, the prevalence of anemia during pregnancy is a well-recognized phenomenon $[35,36]$. The major causative factors implicated in the emergence of anemia during pregnancy are iron-deficiency, folate-deficiency, and vitamin B12 deficiency [37-39]. During pregnancy, the body produces an increased amount of blood in order to support the growth and nutrient requirements of the fetus developing inside the mother's womb. If pregnant women do not get enough iron or certain other nutrients, the body might not be able to produce enough red blood cells to constitute the additional blood. While it is normal to have mild anemia during pregnancy, even after adjusting the hemoglobin level for pregnancy as per WHO guidelines, $52.08 \%$ of pregnant women in Bangladesh are suffering from anemia, of which $13.88 \%$ fall in the moderately or severely anemic category (Table 1). Furthermore, anemia from iron deficiency is common in lactating women especially following the anemia in pregnancy [40, 41].

There is a lower risk of anemia associated with late reproductive age (Models 2-4) as compared to early reproductive age. This can be explained as a result of the lower frequency of pregnancy during this stage and early marriage in Bangladesh that increases a higher rate of pregnancy in early reproductive age $[42,43]$. The addition of the nutritional status variable (BMI) in Model 4 reduces the likelihoods of anemia in the pregnant women in comparison to their counterpart neither pregnant nor lactating. The results of this study revealed that thin women $\left(\mathrm{BMI}<18.5 \mathrm{~kg} / \mathrm{m}^{2}\right)$ were marginally more likely to be anemic as compared to women of normal BMI (Table 4). It is well known that being underweight is a risk factor for anemia especially if the low BMI is caused by insufficient diet [44]. Hence, improving the nutritional status (BMI) in thin women within the study population may have the potential to combat the situation.

Several studies from developing countries have documented that low SES is the main factor in being underweight [45-47]. Therefore, it can be postulated that in order to improve the BMI in thin women in Bangladesh, greater emphasis should be given to improve SES as well as education. Although this study reveals that being classified as normal or overweight is somewhat protective, more than $42 \%$ (see Table 2) of women with a normal BMI $\left(18.50-24.99 \mathrm{~kg} / \mathrm{m}^{2}\right)$ were moderately or severely anemic. Additionally, more than $30 \%$ of overweight (BMI $25-30 \mathrm{~kg} / \mathrm{m}^{2}$ ) women (Table 2) were also victim of some type of anemic disorders suggesting that this subgroup might be influenced by factors other than obvious resource constraints [48]. 
This study included certain special features that deserve to be mentioned, such as (a) the prevalence of anaemia was adjusted for altitude and smoking using the CDC formula adopted by WHO [21, 49]; (b) the order logit model was used to increase the robustness of estimates as well as to account for complex survey design strata, while the clustering variables were used for fitting the model for statistical analysis; (c) BDHS ensured that the interviewers were trained extensively and that the standardized measurement tools and techniques were used in the study. Despite the aforementioned strengths, this study also had some limitations. For example, this study did not include lifestyle parameters of the test subjects, including diet variables and other biomarkers of nutritional deficiencies such as folate, vitamin B12, and vitamin-A deficiency, all of which may impact the hemoglobin concentration. Furthermore, the information on acute and chronic inflammation, parasitic infections, and inherited or acquired disorders that affect hemoglobin synthesis were also ignored. The incorporation of these parameters in future studies will be helpful in a proper identification of potential factors that contribute toward the development of anemia.

\section{Conclusions}

The findings of this study with respect to anemia present a complex scenario that is controlled not only by the household economic status but also by education, diabetes, pregnancy, and nutritional status (BMI), which are associated as a causal factor of anemia. Therefore, the country should employ strategies to reduce diabetes and should consider in its policy strategy reducing the anemia during pregnancy, for example, the iron supplementation during pregnancy.

\section{Abbreviations}

OR: Odd Ratio; Cl: Confidence Interval; BMI: Body Max Index; SES: Socio Economic Status; NIPORT: National Institute of Population Research and Training; CKD: chronic kidney disease; BDHS: Bangladesh Demographic and Health Survey

\section{Acknowledgements}

Firstly, we would like to thank the Measure DHS program for providing access to DHS datasets. Secondly, we are sincerely grateful to all the mothers and children who were interviewed during the surveys.

\section{Author's contributions}

GMRI performed all the study analysis, drafting and editing the manuscript. The author(s) read and approved the final manuscript.

\section{Authors' information}

Dr. Islam is an epidemiologist in the field of nutrition, food safety, and value chain research. He received his PhD from Tokyo Medical and Dental University in Japan under the Monbukagakusho/MEXT scholarship, in the field of public health. He also holds an MSc in Nutrition and Rural Development from Ghent University, Belgium under the VLIR scholarship program, and a BSc in Agriculture from Khulna University, Bangladesh. Dr. Islam is now serving as a faculty member at Shahjalal University of Science and Technology (SUST), Sylhet, Bangladesh.

\section{Funding}

No funding was available for this study.

\section{Availability of data and materials}

The data that support the findings of this study are available from the DHS website (https://www.dhsprogram.com/) but restrictions apply to the availability of these data, which were used under license for the current study, and so are not publicly available. Data are however available upon reasonable request.

\section{Ethics approval and consent to participate}

The Bangladesh Medical Research Council (BMRC) and ICF Macro International approved BDHS. The dataset was requested for access to DHS program website. Informed oral consent were taken from participants before interviewing them as more than one third of the study population is illiterate and the ethics committee of BMRC and ICF Macro International approved it.

\section{Consent for publication}

Before interviewing the survey team orally explain the aim of the BDHS and no personal information will be included during publication as well as the IFC international give permission for the secondary uses and publication.

\section{Competing interests \\ None.}

Received: 27 April 2020 Accepted: 31 January 2021

Published online: 06 February 2021

\section{References}

1. The World Health Organization: The global prevalence of anaemia in 2011. In.; 2015.

2. Balarajan Y, Ramakrishnan U, Özaltin E, Shankar AH, Subramanian S. Anaemia in low-income and middle-income countries. Lancet. 2012; 378(9809):2123-35.

3. Stevens GA, Finucane MM, De-Regil LM, Paciorek CJ, Flaxman SR, Branca F, Peña-Rosas JP, Bhutta ZA, Ezzati M, Group NIMS. Global, regional, and national trends in haemoglobin concentration and prevalence of total and severe anaemia in children and pregnant and non-pregnant women for 1995-2011: a systematic analysis of population-representative data. Lancet Glob Health. 2013;1(1):e16-25.

4. Global Nutrition Targets 2025: AnaemiaPolicy Brief (WHO/NMH/NHD/14.4) [http://apps.who.int/iris/bitstream/handle/10665/148556/WHO_NMH_ NHD_14.4_eng.pdfijsessionid = 5F38732372B9D8E6BD8B9AD4A5FD2B70? sequence $=1$ ]

5. Rahman MM, Abe SK, Rahman MS, Kanda M, Narita S, Bilano V, Ota E, Gilmour S, Shibuya K. Maternal anemia and risk of adverse birth and health outcomes in low-and middle-income countries: systematic review and meta-analysis, 2. Am J Clin Nutr. 2016;103(2):495-504.

6. Allen LH. Anemia and iron deficiency: effects on pregnancy outcome. Am J Clin Nutr. 2000;71(5):1280S-4S.

7. Black MM. Integrated strategies needed to prevent iron deficiency and to promote early child development. J Trace Elem Med Biol. 2012;26(23):120-3.

8. Fu G, Lai J, Chen C. Study on the effect of malnutrition and anemia identified among general population in 2002 To the future productivity in China. Zhonghua liu xing bing xue za zhi. 2006;27(8):651-4.

9. Awofisoye Ol, Adeleye JO, Olaniyi JA, Esan A. Prevalence and correlates of anemia in type 2 diabetes mellitus: a study of a Nigerian outpatient diabetic population. Sahel Medical Journal. 2019;22(2):55.

10. Biswas T, Islam A, Rawal L, Islam S. Increasing prevalence of diabetes in Bangladesh: a scoping review. Public Health. 2016;138:4-11.

11. The World Health Organization: Worldwide prevalence of anaemia 19932005. In.; 2008.

12. The World Health Organization: Iron Deficiency Anaemia Assessment, Prevention, and Control A guide for programme managers. In., vol. WHO/ NHD/01.3; 2001

13. Eicher-Miller HA, Mason AC, Weaver CM, McCabe GP, Boushey CJ. Food insecurity is associated with iron deficiency anemia in US adolescents. Am J Clin Nutr. 2009;90(5):1358-71. 
14. Prüss-Ustün A, Bartram J, Clasen T, Colford JM Jr, Cumming O, Curtis V, Bonjour S, Dangour AD, De France J, Fewtrell L. Burden of disease from inadequate water, sanitation and hygiene in low-and middle-income settings: a retrospective analysis of data from 145 countries. Tropical Med Int Health. 2014;19(8):894-905.

15. National Institute of Population Research and Training: Bangladesh Demographic and Health Survey 2011. In.: National Institute of Population Research and Training, Dhaka, Bangladesh, Mitra and Associates Dhaka, Bangladesh MEASURE DHS, ICF International, Calverton, Maryland, U.S.A; 2013.

16. Bentley ME, Griffiths PL. The burden of anemia among women in India. Eur J Clin Nutr. 2003;57(1):52-60.

17. Eckhardt CL, Torheim LE, Monterrubio E, Barquera S, Ruel MT. The overlap of overweight and anaemia among women in three countries undergoing the nutrition transition. Eur J Clin Nutr. 2008;62(2):238-46.

18. Kefiyalew F, Zemene E, Asres Y, Gedefaw L. Anemia among pregnant women in Southeast Ethiopia: prevalence, severity and associated risk factors. BMC research notes. 2014;7:771.

19. Melku M, Addis Z, Alem M, Enawgaw B. Prevalence and predictors of maternal Anemia during pregnancy in Gondar, Northwest Ethiopia: an institutional based cross-sectional study. Anemia. 2014;2014(6):1-9.

20. National Institute of Population Research and Training MaA, \& Macro International: Bangladesh Demographic and Health Survey, 2011. In. Dhaka, Bangladesh and Calverton, Maryland, USA; 2013.

21. Haemoglobin concentrations for the diagnosis of anaemia and assessment of severity [http://www.who.int/vmnis/indicators/haemoglobin.pdf].

22. National Institute of Population Research and Training MaA, \& Macro International: Bangladesh Demographic and Health Survey, 2011. In. Dhaka, Bangladesh and Calverton, Maryland, USA; 2011.

23. Rutstein S: Wealth versus expenditure: comparison between the DHS wealth index and household expenditures in four departments of Guatemala. In. Calverton, Maryland, USA: ORC Macro 1999.

24. Bharadwaj JA, Kendurkar SM, Vaidya PR. Age and symptomatology of menopause in Indian women. J Postgrad Med. 1983;29(4):218-22.

25. NIPORT et al.: National Institute of Population Research and Training (NIPORT), Mitra and Associates, and ICF International., Bangladesh Demographic and Health Survey 2011. . In. Dhaka, Bangladesh and Calverton, Maryland, USA: NIPORT, Mitra and Associates, and ICF International; 2013.

26. American diabetes association. Diagnosis and classification of diabetes mellitus. Diabetes Care. 2010;33(1):S62-9.

27. The World Health Organization. Definition and diagnosis of diabetes mellitus and intermediate hyperglycaemia: report of a WHO/IDF consultation. Geneva, Switzerland: World Health Organization; 2006.

28. Quantitative Techniques for Health Equity Analysis-Technical Note \#7 [http:// pubdocs.worldbank.org/en/383951503324880315/HealthEquityCh7.pdf].

29. Institute of Medicine $U$ : Weight gain during pregnancy: reexamining the guidelines. In.: Washington, DC. National Academies Press; 2009. (c2009 National Academy of Sciences.; 2009.

30. Gracey M, King M: Indigenous health part 1: determinants and disease patterns. Lancet (London, England) 2009, 374(9683):65-75.

31. Ruel M, Garrett J, Haddad L. In: Rapid Urbanization and the Challenges of Obtaining Food and Nutrition Security. edn.; 2008: 639-656.

32. Glasier A, Gülmezoglu AM, Schmid GP, Moreno CG, VanLook PF. Sexual and reproductive health: a matter of life and death. Lancet. 2006:9547:1595-607.

33. Pop-Busui R. Cardiac autonomic neuropathy in diabetes: a clinical perspective. Diabetes Care. 2010;33(2):434-41.

34. Thomson CA, Stanaway JD, Neuhouser ML, Snetselaar LG, Stefanick ML, Arendell L, Chen Z. Nutrient intake and anemia risk in the women's health initiative observational study. J Am Diet Assoc. 2011;111(4):532-41.

35. Organization WH, Society KCFWsHi: mental health aspects of women's reproductive health: a global review of the literature: World Health Organization; 2009.

36. Black RE, Allen LH, Bhutta ZA, Caulfield LE, De Onis M, Ezzati M, Mathers C, Rivera J. Maternal, group CUS: maternal and child undernutrition: global and regional exposures and health consequences. Lancet. 2008;371(9608):243-60.

37. WJr S, Thurnau GR. Iron deficiency anemia in pregnancy. Clin Obstet Gynecol. 1995;38(3):443-54.

38. Vargas-Ruiz AG, Hernández-Rivera G, Herrera MF. Prevalence of Iron, Folate, and vitamin B12 deficiency Anemia after laparoscopic roux-en-Y gastric bypass. Obes Surg. 2008;18(3):288-93.
39. Yajnik CS, Deshpande SS, Jackson AA, Refsum H, Rao S, Fisher DJ, Bhat DS, Naik SS, Coyaji KJ, Joglekar CV, et al. Vitamin B12 and folate concentrations during pregnancy and insulin resistance in the offspring: the Pune maternal nutrition study. Diabetologia. 2008;51(1):29-38.

40. Innis SM. Impact of maternal diet on human milk composition and neurological development of infants. Am J Clin Nutr. 2014;99(3):734S-41S.

41. Bodnar LM, Scanlon KS, Freedman DS, Siega-Riz AM, Cogswell ME. High prevalence of postpartum anemia among low-income women in the United States. Am J Obstet Gynecol. 2001;185(2):438-43.

42. Mehnaz S, Afzal S, Khalil S, Khan Z. Impact of Iron, Folate, and vitamin C supplementation on the prevalence of Iron deficiency Anemia in nonpregnant females of Peri-urban areas of Aligarh. Indian J Community Med. 2006;31(3):30-2.

43. Field E, Ambrus A. Early marriage, age of menarche, and female schooling attainment in Bangladesh. J Polit Econ. 2008;116(5):881-930.

44. Aronson D, Nassar M, Goldberg T, Kapeliovich M, Hammerman H, Azzam ZS. The impact of body mass index on clinical outcomes after acute myocardial infarction. Int J Cardiol. 2010;145(3):476-80.

45. Ball K, Crawford D: Socioeconomic status and weight change in adults: a review. Social science \& medicine (1982) 2005, 60(9):1987-2010.

46. Nube M, Asenso-Okyere WK, van den Boom GJ. Body mass index as indicator of standard of living in developing countries. Eur J Clin Nutr. 1998; 52(2):136-44.

47. Pelletier DL, Rahn M. Trends in body mass index in developing countries. Food Nutr Bull. 1998;19(3):223-39.

48. Griffiths $P$, Stephenson R. Understanding users' perspectives of barriers to maternal health care use in Maharashtra, India. J Biosoc Sci. 2001;33(3):339-59.

49. Centers for Disease Control and Prevention. Recommendations to Prevent and Control Iron Deficiency in the United States. 1998. https://www.cdc. $\mathrm{gov} / \mathrm{mmwr} / \mathrm{preview} / \mathrm{mmwrhtml} / 00051880 . \mathrm{htm}$.

\section{Publisher's Note}

Springer Nature remains neutral with regard to jurisdictional claims in published maps and institutional affiliations.

Ready to submit your research? Choose BMC and benefit from:

- fast, convenient online submission

- thorough peer review by experienced researchers in your field

- rapid publication on acceptance

- support for research data, including large and complex data types

- gold Open Access which fosters wider collaboration and increased citations

- maximum visibility for your research: over $100 \mathrm{M}$ website views per year

At BMC, research is always in progress.

Learn more biomedcentral.com/submissions 